\section{Commentary: Radial artery tips from Melbourne: We stand on the shoulder of giants}

\author{
N. Bryce Robinson, MD, and Mario Gaudino, MD
}

While we owe the reintroduction of the radial artery (RA) in coronary artery bypass surgery to Acar and colleagues, ${ }^{1}$ most of the data on its patency and outcomes come from Australia, and in particular from Melbourne, where Buxton, Tatoulis, and Hare have been leading the field for almost 3 decades.

In this issue of the Journal, Tatoulis, a recognized expert in the field of multiple arterial grafting (MAG), presents a pragmatic approach to harvesting and preservation of the RA. $^{2}$ Due to its demonstrated superior patency rate, the RA is now used with increased frequency in international coronary practices. ${ }^{3,4}$ The recently published long-term results of the Radial Artery Patency and Clinical Outcomes (RAPCO) trial showed a significantly greater 10-year patency rate of the RA when compared with the free right internal thoracic artery and the saphenous vein., ${ }^{5,6}$ As such, the RA now seems to be the logical second choice following the gold standard left internal thoracic artery for coronary artery bypass grafting.

Our group has learned much from Tatoulis and others out of Royal Melbourne Hospital, and this expert review is no exception. We use similar screening and preservation techniques as well as operative strategies. As is highlighted, it is our routine practice to use a combination of the modified Allen test with either duplex ultrasonography or index finger plethysmography to evaluate the RA for harvesting. While the time cut-off for the modified Allen

From the Department of Cardiothoracic Surgery, Weill Cornell Medicine, New York, NY.

Disclosures: The authors reported no conflicts of interest.

The Journal policy requires editors and reviewers to disclose conflicts of interest and to decline handling or reviewing manuscripts for which they may have a conflict of interest. The editors and reviewers of this article have no conflicts of interest.

Received for publication Oct 8, 2020; revisions received Oct 8, 2020; accepted for publication Oct 20, 2020; available ahead of print Oct 22, 2020.

Address for reprints: Mario Gaudino, MD, Department of Cardiothoracic Surgery, Weill Cornell Medicine, 525 E 68th St, New York, NY 10065 (E-mail: mfg9004@med.cornell.edu).

JTCVS Techniques 2021;5:58-9

2666-2507

Copyright $(2020$ The Authors. Published by Elsevier Inc. on behalf of The American Association for Thoracic Surgery. This is an open access article under the CC BY-NCND license (http://creativecommons.org/licenses/by-nc-nd/4.0/).

https://doi.org/10.1016/j.xjtc.2020.10.030

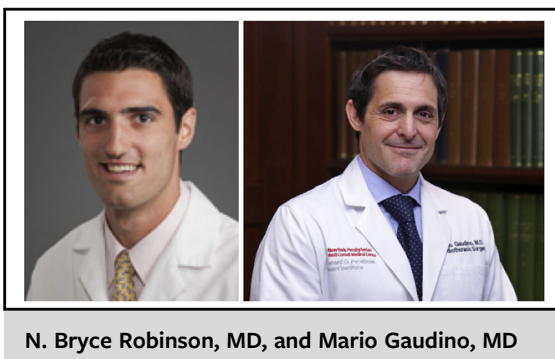

CENTRAL MESSAGE

As the radial artery emerges as

the best second conduit in coronary artery bypass grafting, the coronary surgeon must become familiar with pre- and intraoperative considerations and techniques.

test is unclear, 10 seconds seems to be an appropriate length of time after which the RA should not be used or further testing pursued. ${ }^{7}$

If the RA is deemed suitable, our group favors the open harvesting technique, as we feel the endothelial integrity is better preserved using this approach. ${ }^{8}$ It is also important to note that most randomized evidence evaluating the RA is derived from trials using the open harvesting technique, including RAPCO. Endoscopic harvesting may be an alternative for experienced operators. Avoiding electrocautery and using the harmonic scalpel may decrease the risk of vasospasm and thermal damage to the RA conduit. We preserve the RA in buffered verapamil/nitroglycerine or papaverine in an asanguineous bath.

Once prepared for anastomosis, the RA is usually used as a free graft with an aortocoronary proximal anastomosis. The composite $\mathrm{Y}$ configuration can increase the number of distal coronary anastomoses but carries a greater risk of flow maldistribution and failure due to competitive flow. Popularized by the author of this expert review, the "Baby Y" graft is a superb technical solution when the coronary anatomy is not suitable for a sequential anastomosis. ${ }^{9}$

As MAG emerges as the superior revascularization strategy, the coronary surgeon will need to become increasingly comfortable with the RA. While there are a number of preand intraoperative considerations, when used in the right setting the RA offers superior long-term patency and outcomes. Our hats go off to Tatoulis not only for ushering the era of MAG but also providing us with pragmatic expert 
reviews such as this to guide surgeons not familiar with RA coronary artery bypass grafting.

\section{References}

1. Acar C, Jebara VA, Portoghese M, Beyssen B, Pagny JY, Grare P, et al. Revival of the radial artery for coronary artery bypass grafting. Ann Thorac Surg. 1992;54: 652-9; discussion 659-60.

2. Tatoulis J. The radial artery: an important component of multiarterial coronary surgery and considerations for its optimal harvest. J Thorac Cardiovasc Surg Tech. 2021;5:46-55.

3. Gaudino M, Benedetto U, Fremes S, Biondi-Zoccai G, Sedrakyan A, Puskas JD, et al. Radial-artery or saphenous-vein grafts in coronary-artery bypass surgery. N Engl J Med. 2018;378:2069-77.

4. Tatoulis J, Buxton BF, Fuller JA, Meswani M, Theodore S, Powar N, et al. Longterm patency of 1108 radial arterial-coronary angiograms over 10 years. Ann Thorac Surg. 2009;88:23-9; discussion 29-30.
5. Buxton BF, Hayward PA, Raman J, Moten SC, Rosalion A, Gordon I, et al. Long term results of the RAPCO trials. Circulation. 2020;142:1330-8.

6. Gaudino M, Benedetto U, Fremes S, Ballman K, Biondi-Zoccai G Sedrakyan A, et al. Association of radial artery graft vs saphenous vein graft with long-term cardiovascular outcomes among patients undergoing coronary artery bypass grafting: a systematic review and meta-analysis. JAMA. 2020; 324:179-87.

7. Ruengsakulrach P, Eizenberg N, Fahrer C, Fahrer M, Buxton BF. Surgical implications of variations in hand collateral circulation: anatomy revisited. J Thorac Cardiovasc Surg. 2001;122:682-6.

8. Gaudino MF, Lorusso R, Ohmes LB, Narula N, McIntire P, Gargiulo A, et al. Open radial artery harvesting better preserves endothelial function compared to the endoscopic approach. Interact Cardiovasc Thorac Surg. 2019;29:561-7.

9. Gaudino M, Fremes S, Schwann TA, Tatoulis J, Wingo M, Tranbaugh RF. Technical aspects of the use of the radial artery in coronary artery bypass surgery. Ann Thorac Surg. 2019;108:613-22. 